\title{
Dynamic Competition and Cooperation of Road Infrastructure Investment of Multiple Tourism Destinations: A Case Study of Xidi and Hongcun World Cultural Heritage
}

\author{
Jun Li, ${ }^{1}$ Wenna Zhang, ${ }^{1}$ Honggang $\mathrm{Xu},{ }^{2}$ and Jie Jiang ${ }^{3}$ \\ ${ }^{1}$ Guangdong Provincial Key Laboratory of Intelligent Transportation System, School of Engineering, Sun Yat-sen University, \\ Guangzhou 510006, China \\ ${ }^{2}$ School of Tourism, Sun Yat-sen University, 135 Xingang West Road, Guangzhou 510275, China \\ ${ }^{3}$ Shenzhen Urban Transport Planning Center, Shenzhen 518021, China
}

Correspondence should be addressed to Jun Li; stslijun@mail.sysu.edu.cn

Received 31 December 2014; Accepted 11 March 2015

Academic Editor: Alicia Cordero

Copyright ( 92015 Jun Li et al. This is an open access article distributed under the Creative Commons Attribution License, which permits unrestricted use, distribution, and reproduction in any medium, provided the original work is properly cited.

\begin{abstract}
The transportation infrastructure always plays an important role in the development of the local tourism. A system dynamics method incorporated with a destination choice model is proposed in this paper to analyze the dynamic impacts of transportation infrastructure on the tourism development, where multiple tourism destinations share a common market. Tourists' destination choice behaviors are characterized by a multinomial logit choice model based on the utility of destinations, which depends heavily on the accessibility of destinations that the local administration has strong willingness to improve. The system dynamics method is used to model dynamic interactions among destinations and to simulate the dynamic evolution of the competition on the tourism market. A case study of the World Cultural Heritage Sites, Xidi and Hongcun villages, shows the competition for road infrastructure investment can produce a win-win situation and bring the cooperation on investment due to the positive externality of transport infrastructure and two villages show a tendency to merge into one bigger destination. Finally, the tourism development strategies for two villages are discussed based on the scenario analysis.
\end{abstract}

\section{Introduction}

Generally it is believed that the accessibility of tourism destinations has significant impacts on the tourism development, as the improvement of transport infrastructure can significantly reduce the trip cost. An integrated model was proposed in 2001 for quantifying the accessibility benefits in developing countries, in which accessibility-enhancing strategies are formulated by a set of constraints, and an optimal package of different investment strategies can be planned [1]. Actually the transport infrastructure is recognized as a basic component of successful creation of new attractions as well as for healthy growth of existing ones. It can be viewed as a potential determinant of the attractiveness of those destinations [2,3]. Recent empirical studies show that destinations with wellbuilt transport infrastructure attract more tourists [4-6]. So the transport infrastructure is a key factor in determining the market share where multiple tourism destinations with similar attractiveness share the same tourist market. Besides, the market share of tourism destinations is closely related to the choice behavior of tourists. However the studies mentioned above generally acknowledge the necessity for efficient transport and present useful approaches to study the relationship between the transportation and the tourism, but the role of transport infrastructure and its relationship with the tourist choice behavior have not been investigated thoroughly.

The transport infrastructure plays a key role in tourist trip costs (such as time cost and monetary cost), so tourist behaviors can be studied in the economics theory $[7,8]$. It is observed that tourists may seek alternative destinations if they are inhibited by inefficiencies in the transport $[9,10]$. In order to analyze the tourist choice behavior, a classical 
transport cost model including all costs in a touring trip, such as journey time cost, price cost, comfort of the journey, and transport infrastructure cost at destination, is proposed and every tourist faces a choice problem in finding a suitable destination within their budget that constrains the choice [11]. Other factors affecting destination choice include the travel experience of transport vehicles and infrastructure, which states that the transport process can also provide a tourism experience and should be integrated delicately into the whole touring arrangement in order to maximize tourists' benefit [12-14]. The tourist choice behavior can be calculated by a modal split method, because each tourist choice is viewed as one mode whose utility is based on the quality of infrastructure [15-17]. The discrete choice model is widely used to calculate the market share of different tourism products or modal spilt in tourism trips $[18,19]$. However, most studies on tourist choice behavior are static methods, which have difficulty in capturing the dynamic interaction among transport infrastructure, tourist behavior, and destination development.

Since every tourist destination wants to improve its market share, the competition for the transport infrastructure is unavoidable. But, in the actual situation, the impact of the transport infrastructure is an interrelated process of multiple tourism destinations, because the construction of the transport infrastructure demonstrates a positive externality and the accessibility enhancement can spread through the transport network. The areas not directly connected to the new infrastructure may also benefit from the opening of new roads and this positive externality of transport infrastructure is especially strong when the transport network of the whole region is poor. So the result of the competition for transport infrastructure from tourist destinations may be diverse and a win-win situation is possible. Thus the influence of the transport infrastructure on the tourism development of tourist destinations is a dynamic process in practice.

This study aims to demonstrate the dynamic development process of multiple tourism destinations, which evolves the competition and the cooperation relationship of transport infrastructure investment. A system dynamics method is utilized in this paper to simulate the interaction of road infrastructure investment and the tourism development of destinations and incorporates a logit choice model to describe tourism destination choice behavior. A generic model is built and then applied in a real case. Through the simulation of the real case, insights into the transportation infrastructure are obtained. Because of the positive externality of the transport infrastructure, the relationship of the competing tourism destinations turns into a win-win situation, which provides a good enlightenment to the local management.

\section{Framework to Simulate Tourism Destination and Transportation Development}

To capture dynamic characteristics of the development process of tourism destinations and to simulate the dynamic decision-making of tourists, a system dynamics method incorporated with choice modeling is proposed. The use of the system dynamics approach is to simulate the evolution of the multiple destination development process over time, while the multinomial logit model (short for MNL) is used to describe tourists' choice behavior at decision-making points. The combination of two methods makes it easy to analyze the dynamic evolution of tourism behavior.

2.1. Basic Assumptions. To simplify the complexity of tourism destination development, multiple destinations are assumed to be located in one region and share the same potential tourist market, and tourists are assumed to have no preference for destinations in the view of scenery. The tourists face a number of choices, such as visiting one destination only or visiting more than one destination; each choice is treated as a product in the model; the probability to choose a product is determined by the utility of that product.

It is also assumed that the attractiveness effect of the road-building strategy is a short term reaction of tourists toward the decrease in trip costs, but whether it is sustainable depends also on the capacity of the tourism destination determined by the nature of the destination and the land management of the destination. The long term effect of road infrastructure competition is obtained by a dynamic system simulation involving the road infrastructure and the destination choice behavior of tourists as well as the destination land management.

Since the purpose of this study is to uncover the relationship between the road infrastructure investment and the destination tourism development in China, some additional assumptions should be proposed at the beginning: (1) that the studied region is located in an undeveloped area where the road network is not well developed; (2) that the studied region contains two or more identical destinations that are eager for tourism development; (3) that the tourists prefer to visit as many destinations as possible in their time budget if other requirements are met.

2.2. System Dynamics Framework. System dynamics is an approach to modeling the behavior of complex systems over time by using feedback loops, stocks, and flows [20]. This method has been proved to be an effective tool to deal with internal feedback loops and time delays that affect the behavior of an entire system. As shown in Figure 1, the proposed framework involves tourism development, transport infrastructure, and destination capacity and contains two major negative feedback loops, namely, the feedback of tourism arrival and the feedback of destination capability, which are connected by the variable of destination crowdedness.

The crowdedness, which is a function of the destination capacity and number of tourists, affects tourist behavior and meanwhile provides future directions for the destination management to improve. A high density of tourists would lead to poor experience; this may cause the loss of attractiveness and the reduction in crowdedness. When the management feels that the destination is too crowded, the local management could intend to increase the destination capacity, for instance, encroachment on cultivated land to decrease crowdedness and attract more tourists. This negative 


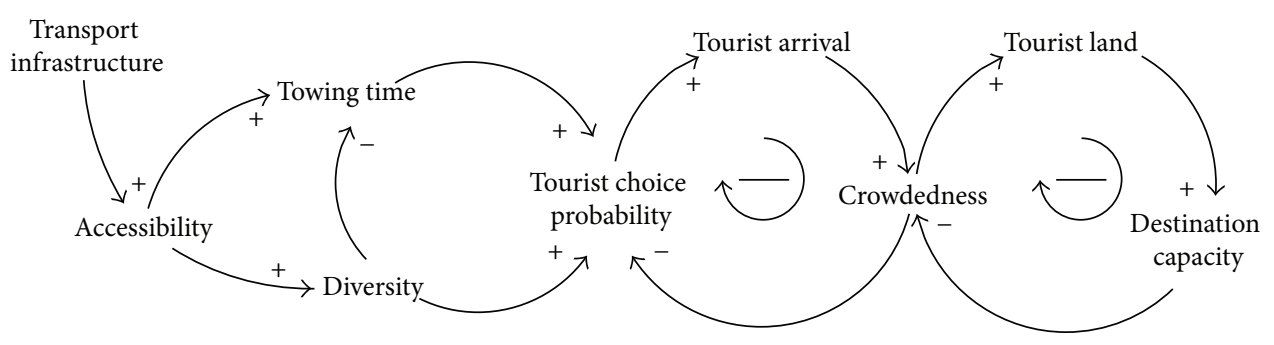

FIGURE 1: Feedback in system dynamics framework.

feedback reflexes a self-regulated mechanism of management team.

In the feedback loops, the crowdedness, the tourist arrival at the village, and the possibility for tourists to choose one particular attraction are also linked with each other. When tourists choose one particular attraction, it will increase crowdedness in the site. The higher degree of crowdedness would reduce the possibility for future tourists to visit this place and increase the possibility to choose other tourism destinations.

Transport infrastructure has positive impacts on destination accessibility, which cuts down trip time and brings tourists more opportunities to visit more destinations within a given time. However the new-road construction consumes long time and the opening of transportation infrastructure is discrete; therefore the transportation infrastructure is treated as external variable and is defined through scenario analysis.

2.3. Destination Choice Behavior Modeling. The MNL choice model, which has been used to analyze the decision-making process of tourist choice on multiple destinations, has been successfully applied in the fields of transport modal split and route choice [21, 22]. In this paper, the MNL choice model is proposed to calculate the market share of tourism products. It is assumed that the possibility of tourists choosing a product is determined by the utility of the product. Three major factors affecting the utility are considered in this study: trip cost, representing the time and money that a tourist spends on the journey from an origin to destinations; the numbers of the destinations they can visit; and the level of crowdedness.

\section{Case Study}

Listed as World Heritage Sites by the United Nations Educational, Scientific and Cultural Organization (UNESCO) in 2000, Xidi and Hongcun are two adjacent historical villages in southern Anhui province (both villages belong to Yi County, Huangshan City) that are famous for their well-preserved Hui-style architecture [23]. Xidi village is entitled the "Ming and Qing Dynasty Local Residence Museum" and Hongcun village has earned the reputation for being "a village in the beautiful Chinese picture." The major tourist source for the two villages is those who visit Mt. Huang, one of the most famous natural attractions and in the top tier of tourism destinations in China [24]. Tourist arrivals of Mt. Huang are around 1.5 million every year.
The case of Xidi (XD) and Hongcun (HC) is typical in demonstrating the competition and cooperation of road infrastructure investment. Firstly, Xidi and Hongcun are somewhat isolated for a long time so that they are wellpreserved even in the era of recent urbanization. Secondly, the competition between Xidi and Hongcun is unavoidable because the two villages are very close and share the same tourist market, and it is a good example to show that the improvement of road infrastructure in one village can also bring impacts to the other. Thirdly, as the unique selling points of the two villages are almost identical and remain unchanged in the long term, local management believes that improvement in road infrastructure is the only way to increase destination attractiveness, making two villages a good case to observe the effects of road infrastructure on tourism destinations.

The field work for Xidi and Hongcun was carried out in August of 2008 and 2009 using semistructured interview method. Major stakeholders were interviewed to obtain a panoramic perspective on the issues relating to tourist behaviors, business development, infrastructure investment, and policies on heritage conservation and tourism development. The main stakeholders include (a) the management committees from Xidi and Hongcun; (b) travel agencies; (c) local business owners; (d) local residents; and (e) tourists. Questionnaire survey was also conducted to understand tourist behaviors. The questions included the major determinant factors of the trip, such as the origin of the trip, the destination of the trip, travel modes, travel routes, the destination choice, touring time for each destination, and also their comments on two destinations (including the aspects of the crowdedness and the diversity). A total of 138 effective questionnaires were collected. The socioeconomic data were collected from the Statistics Bureau of Yi County. The tourism development characteristics of Hongcun and Xidi from previous studies are also considered to support the development of the decisionmaking process, which include the land use change [25], tourist experience [24, 26], and tourism management [27].

3.1. Tourism and Road Infrastructure Development of Xidi and Hongcun. Although the tourism development was back to 1986, two villages were typical villages in southern Anhui Province, dominated by agriculture, poor infrastructure, and low GDP, before they were acknowledged by UNESCO. Taking advantage of their great reputation as well as influence brought via official approval, the tourism at two villages came into a new era and replaced agriculture as the dominant 


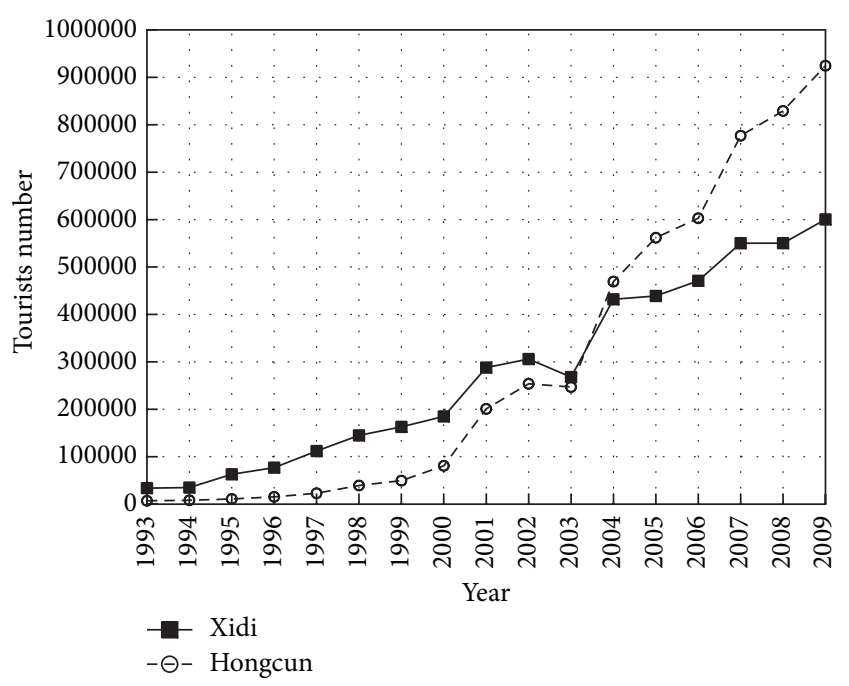

Figure 2: Comparison of tourist numbers between Xidi and Hongcun.

industry in 2001, only one year after they became World Heritage Sites [28]. Rapid growth in tourist numbers had been observed between 2000 and 2008 for both villages, as shown in Figure 2.

From the view of the transportation infrastructure, Xidi had a location advantage over Hongcun before 2003, as it was closer to Mt. Huang in the original road network, so that Xidi obtained more revenue from the tourism than Hongcun. The opening of the Hong-Ru Road in late 2003, a direct link between Hongcun and Mt. Huang, significantly changed the competition situation, as Hongcun became more accessible to the major market and Hongcun got more tourism revenue than Xidi in 2004. To compete with Hongcun, Xidi takes an "eye-to-eye" strategy: it plans to build a new road named the $\mathrm{Xi}-\mathrm{Ru}$ Road as shown in Figure 3, which reduces the travel distance to Mt. Huang by about $22 \mathrm{~km}$ and makes the time cost of the Xidi trip almost equivalent to that of Hongcun.

Although the growth rate of tourist numbers for Xidi was lower than that for Hongcun between 2003 and 2008, it was still higher than the growth rate of Mt. Huang, since the Hong-Ru Road also reduced the travel time to Xidi. The results implied that both villages may benefit from new road infrastructure improvement, leading to cooperation on building the Xi-Hong Road (see Figure 3), which is supposedly invested by both villages. The opening of the $\mathrm{Xi}$ Hong Road would reduce the travel distance between Xidi and Hongcun from $19 \mathrm{~km}$ to $10 \mathrm{~km}$.

3.2. A System Dynamics Model of Xidi and Hongcun. The proposed generic system dynamics model for destination development has been further developed to reflect the situation of Hongcun and Xidi. The integrated model has three sectors, tourist, transport infrastructure, and land use, which determines the capacity of the attraction.

To be able to simulate the dynamic process, the feedback model is translated into a stock-flow structure model as shown in Figure 4. Three major stocks were built into the

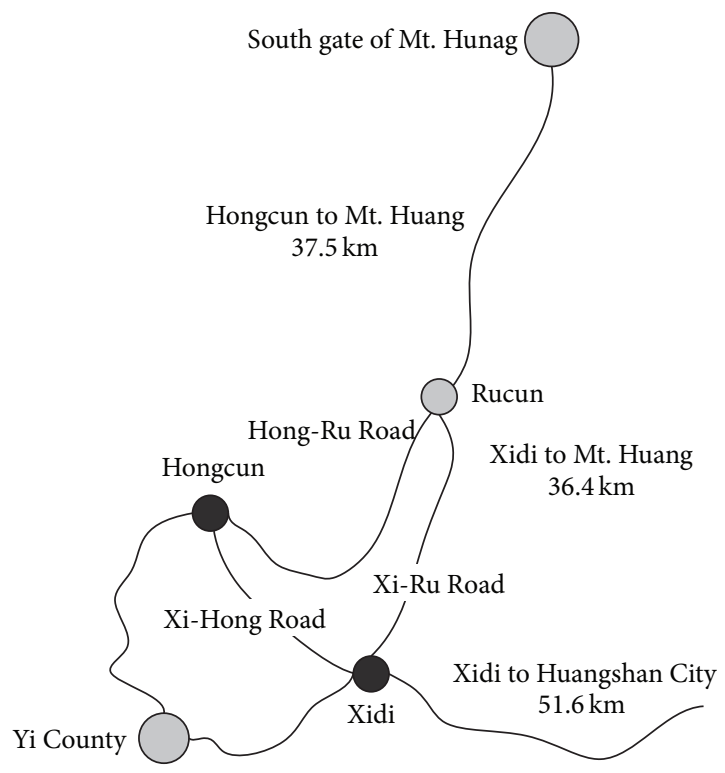

FIgURE 3: The transportation infrastructure of the case.

model, namely, tourists on site, tourist-available land, and the other land. The model of Xidi (XD in Figure 4) and Hongcun (HC) has a symmetrical structure due to identical assumptions on Xidi and Hongcun, where two parts of the model are connected with two negative feedback loops in which tourist choice behavior and the degree of crowdedness are connecting variables.

3.2.1. Tourist Sector. Tourists on site are controlled by tourist arrivals and departures, and the tourist arrival is mainly influenced by the tourism of Mt. Huang and the market share of Yi County:

$$
N_{i}(t)=N_{i}(t-\Delta t)+\left[A_{i}(t)-D_{i}(t)\right] \cdot \Delta t,
$$

where $N_{i}(t)$ is the number of tourists at time $t$ in village $i$, $A_{i}(t)$ is the number of tourist arrivals in village $i$, and $D_{i}(t)$ is the number of tourism departures. $A_{i}(t)$ is determined by the number of tourists in Mt. Huang $N_{H}(t)$, the market share of Yi Country, represented by the ratio of visitors from Mt. Huang visiting Xidi and Hongcun $\rho(t)$, and the market share of village $i P_{i}(t)$ :

$$
A_{i}(t)=\rho(t) \cdot P_{i}(t) \cdot N_{H}(t) .
$$

3.2.2. Land Use Sector. For the case of Xidi and Hongcun historic villages, the whole destination area can be divided into two parts: tourist-available land, referring to the land that has already been developed for tourism, and the other land, referring to land that has other functions unrelated to tourism but has the potential to be converted to the tourist-available land. Since Hongcun and Xidi are historical villages, there are strong regulations on the construction of tall buildings and demolition of existing buildings, and therefore there are limited land and space for tourism activities and the land development is also controlled by the maximum land size of 


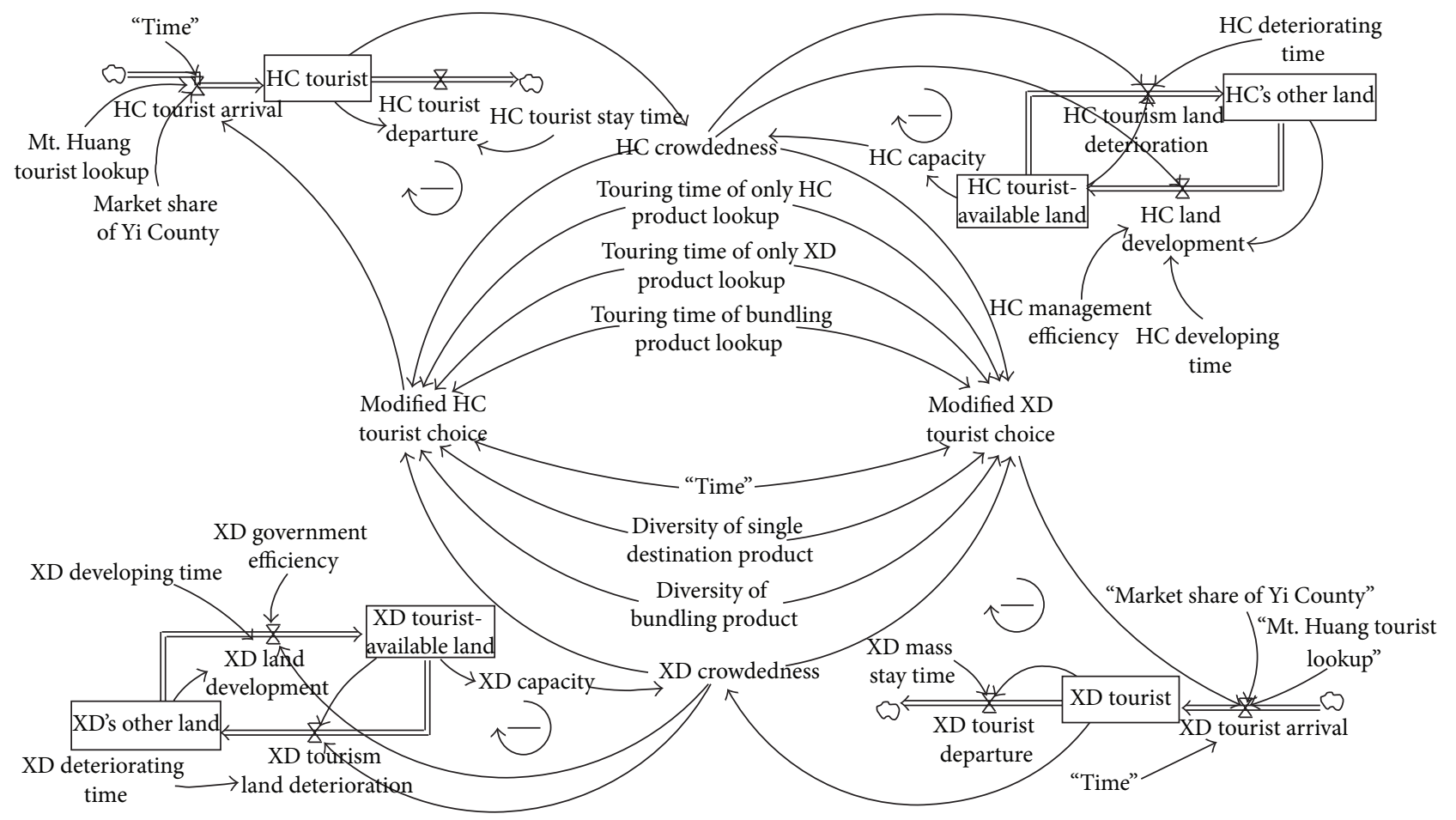

FIGURE 4: System dynamics model of the Xidi and Hongcun case.

the destination. Tourist-available land is increased through the land development from the other land and decreases as a result of deterioration to the other land:

$$
L_{i}^{T}(t)=L_{i}^{T}(t-\Delta t)+\left[R_{i}(t)-Q_{i}(t)\right] \cdot \Delta t,
$$

where $L_{i}^{T}(t)$ is the volume of the tourist-available land at time $t$ in village $i, R_{i}(t)$ is the number of the land developments in village $i$, and $Q_{i}(t)$ is the number of the tourism land deteriorations in village $i$. The volume of the other land at time $t$ in village $i$ is given as

$$
L_{i}^{O}(t)=L_{i}^{O}(t-\Delta t)+\left(Q_{i}(t)-R_{i}(t)\right) \cdot \Delta t .
$$

Tourism land development is determined by the tourism crowdedness, the land management efficiency, and the volume of the other land and the tourism land deterioration is controlled by the tourism crowdedness and the volume of tourist-available land:

$$
\begin{gathered}
R_{i}(t)=\frac{C_{i}(t) \cdot e_{i}(t) \cdot L_{i}^{O}(t)}{T_{i}^{R}}, \\
Q_{i}(t)=\frac{C_{i}(t) \cdot L_{i}^{T}(t)}{T_{i}^{Q}},
\end{gathered}
$$

where $C_{i}(t)$ is the degree of crowdedness of tourists, $T_{i}^{R}$ is the land development time cost in village $i, T_{i}^{\mathrm{Q}}$ is the land deterioration time cost in village $i$, and $e_{i}(t)$ is the land management efficiency.

The crowdedness of tourists brings opportunities for small businesses in these historical villages, for example, the retail business, restaurants, and guest houses, since their business profits are based on the number of tourists. The increase in crowdedness would accelerate the conversion of the other land to tourist-available land, leading to the growth of destination capacity and finally reducing the degree of crowdedness. The profits of shops will drop as the number of visitors drops, and the owners may give up their business; then the lands which are used for tourists would be turned to other uses. In general, the business operators are reluctant to close their shops due to limited alternative business; therefore the time which is needed to transfer the tourism land to other uses is often greater than for transferring other lands to tourism use.

The efficiency of the local management is also considered in the model, as the land development is affected by behaviors of the local government (the land in Xidi and Hongcun is state-owned or collectively owned so that the local government reserves the right to the opening of the new business). The level of efficiency of local management is defined as an external factor in the land-transforming process, which affects the time for the destination development.

3.3. Logit Choice Model Calibration and Validation. The tourists face three choices (products), namely, visiting Xidi only, visiting Hongcun only, or visiting both villages. According to field surveys in 2008 and 2009, the three major factors affecting product choices are the trip time cost, the diversity of the product, and the crowdedness of the destination. The first one represents the tourists' willingness to spend less time in route and have more time in touring; the second one represents tourists' willingness (especially mass tourists) to visit 
TABLE 1: Model parameters estimation.

\begin{tabular}{lcc}
\hline Parameters & Estimated value & $t$-test value \\
\hline$\alpha_{1}$ & -6.9043 & -22.0411 \\
$\alpha_{2}$ & -7.3178 & -40.7228 \\
$\theta_{1}$ & 5.2850 & -14.8057 \\
$\theta_{2}$ & -9.2756 & 118.8821 \\
$\theta_{3}$ & -5.0127 & -53.4237 \\
\hline
\end{tabular}

destinations in a trip so that they can enjoy a more diverse experience if the time is allowed; and the third one indicates tourists' willingness to avoid crowdedness and want good travel experience. The touring time and the diversity may cause conflicts since the total trip time is limited; the diversity means more time cost in route and causes the decrease of touring time for each destination. The tourists have to make a choice in how to balance the touring time and the total number of visited destinations; so the utility of product $i$ is given by

$$
V_{i}(t)=\alpha_{i}+\theta_{1} X_{1 i}(t)+\theta_{2} X_{2 i}(t)+\theta_{3} X_{3 i}(t-1),
$$

where $i=1,2,3$ represents product Xidi only, Hongcun only, and bundling product, respectively; $X_{1 i}(t)$ is the trip time cost in year $t ; X_{2 i}(t)$ is the diversity in year $t ; X_{3 i}(t-1)$ is the crowdedness in year $t-1 ; \theta_{1}, \theta_{2}$, and $\theta_{3}$ are the parameters of $X_{1 i}(t), X_{2 i}(t)$, and $X_{3 i}(t-1)$, respectively; $\alpha_{i}$ is the dummy variable for product $i$ and $\alpha_{3}$ is set to 0 without loss of generality.

The MNL model gives the market share of tourism product $i$ as follows:

$$
\operatorname{Pr}_{i}(t)=\frac{\exp \left[V_{i}(t)\right]}{\sum_{j \in A(t)} \exp \left[V_{j}(t)\right]} .
$$

It is clear that the market share of Xidi in $(7)$ is $P_{1}(t)=$ $\operatorname{Pr}_{1}(t)+\operatorname{Pr}_{3}(t)$ and the market share of Hongcun is $P_{2}(t)=$ $\operatorname{Pr}_{2}(t)+\operatorname{Pr}_{3}(t)$.

The field survey data obtained in 2008 and 2009 were used to obtain five parameters of the logit model, namely, $\theta_{1}, \theta_{2}, \theta_{3}, \alpha_{1}$, and $\alpha_{2}$. The value of the trip time cost is taken from the questionnaire survey. The value of the diversity of a single village is defined as 1 , the value of bundling products is estimated by tourists according to their judgments between 1 and 2, and the value of the crowdedness is represented by the average degree of crowdedness in 2007. A maximum likelihood method is applied to estimated parameters and solved by Newton-Raphson method. Table 1 gives the estimated results. A $t$-test is applied to test the results of parameter estimation. The significant level is set to 0.01 , and all absolute values of $t$ are greater than 2.576, indicating that all variables proposed to describe tourist choice behaviors are effective. The hit rate of the estimated model is $84.26 \%$ and the modified goodness of fit is 0.7757 , both of which indicate that the estimated model has good precision of prediction.

To test the model, a simulation from 2001 to 2009 is carried out in order to compare the observed and simulated results of the number of tourists per year, as shown

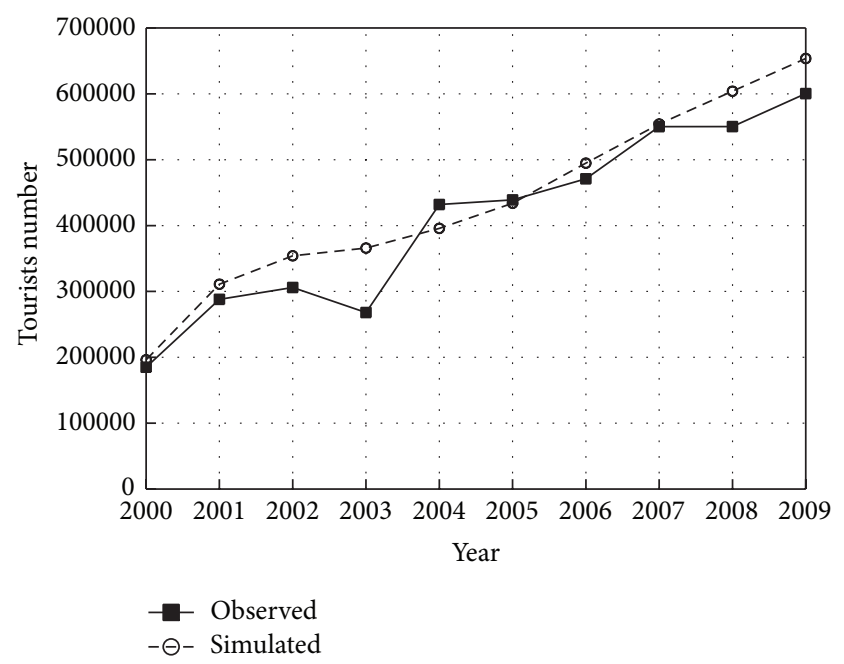

FIGURE 5: Comparison of observed and simulated Xidi tourist numbers.

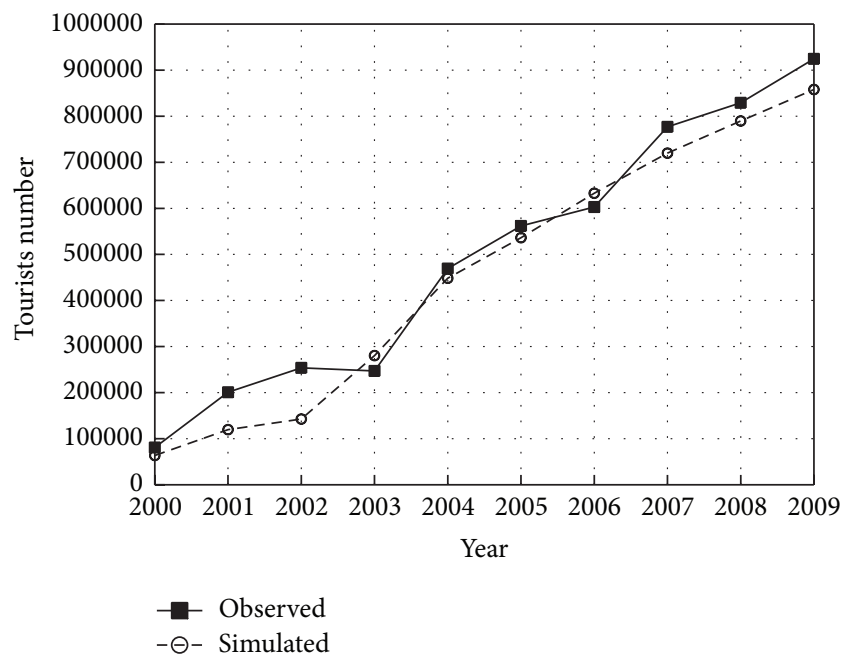

Figure 6: Comparison of observed and simulated Hongcun tourist numbers.

in Figures 5 and 6. The root-mean-square percent errors (RMSPE) of Xidi and Hongcun are 0.1397 and 0.2094 , respectively, and are below 0.25 , indicating that the model replicates historical data well. The drop of the observed tourist number in 2003 was due to SARS, which is not considered in the model.

Two major road infrastructure projects are considered in the scenario analysis: one is the $\mathrm{Xi}-\mathrm{Ru}$ Road (planned in 2010), which is a result of free competition, and the other is the $\mathrm{Xi}$-Hong Road (planned in 2013), which is a result of cooperation. The model is developed based on the following assumptions: (1) trips start from the south gate of Mt. Huang (where the majority of accommodation facilities for Mt. Huang tourism are located); (2) tourists take sightseeing bus (either a local bus or a bus from a travel agency) on the shortest route to the ancient village, with the speed of $50 \mathrm{~km} / \mathrm{h}$; (3) time budget for tourists is 10 hours, from 9 am to 
TABLE 2: Touring time under different road infrastructure conditions (unit: hours).

\begin{tabular}{lcccc}
\hline Tourism product & $\begin{array}{c}2000-2003 \\
\text { Original roadmap }\end{array}$ & $\begin{array}{c}2004-2010 \\
\text { Opening of Hong-Ru }\end{array}$ & $\begin{array}{c}2011-2013 \\
\text { Opening of Xi-Ru }\end{array}$ & $\begin{array}{c}2014- \\
\text { Opening of Xi-Hong }\end{array}$ \\
\hline Only Xidi & 3.56 & 4.64 & 4.64 & 4.64 \\
Only Hongcun & 4.31 & 4.31 & 4.76 & 4.76 \\
Bundling product & 3.56 & 4.10 & 4.33 & 4.49 \\
\hline
\end{tabular}

$7 \mathrm{pm}$, within which they will finish the roundtrip of the two historical villages; (4) 4 hours is spent on eating, rest, and so forth. Based on the assumptions above, the touring time of all the products under different road infrastructure conditions is presented in Table 2 .

3.4. Data Preparation and Calibration. The time unit of the simulation is the year. The efficiency of the management is set to be 1 at the beginning, which means the market's need for the land development can be fully executed by the local management. The deteriorating time for touristavailable land is set to be 3 years, while the developing time of the other land is 1 year, which indicates the different natures of the land deterioration and the land development. In this paper, the land sizes of each destination determine the tourism capacity in the attractions. The land size of Xidi in 2000 is represented by 675,000 persons per year $(2,500$ persons per day) in the available touring days in a year (which is 270 days). Therefore, the initial values for the touristavailable land at the beginning of the simulation are 675,000 for Xidi and 810,000 for Hongcun, while the initial values for the other land at the beginning of the simulation are 405,000 for Xidi and 675,000 persons per year for Hongcun. It should be mentioned that Hongcun is larger than Xidi in both the tourist-available land and the other land at the beginning. The data for touring time of the different tourism products are oriented from data in Table 2 .

\section{Scenario Analysis and Discussion}

4.1. Competition of Road Infrastructure Investment. The scenario is designed to simulate each village building a new road according to their own interests, that is, building the Hong$\mathrm{Ru}$ Road (2000) and the Xi-Ru Road (2010), which results in competition for road infrastructure investment in Xidi and Hongcun. The simulation period is set to be from 2000 to 2012.

Figure 7 shows that the ratio of the Xidi product only drops sharply with the opening of the Hong-Ru Road (2000). The ratio of the Hongcun product only also drops with the opening of the Xi-Ru Road (2010). However, the ratio of bundling product continuously rises in the simulation time, and tourist numbers for two villages keep increasing, as shown in Figure 8. The simulation indicates that the competition for road infrastructure investment has positive effects on the tourism revenue for both destinations, but the village which invested in road infrastructure gets more benefits than the other one which can act as free rider.

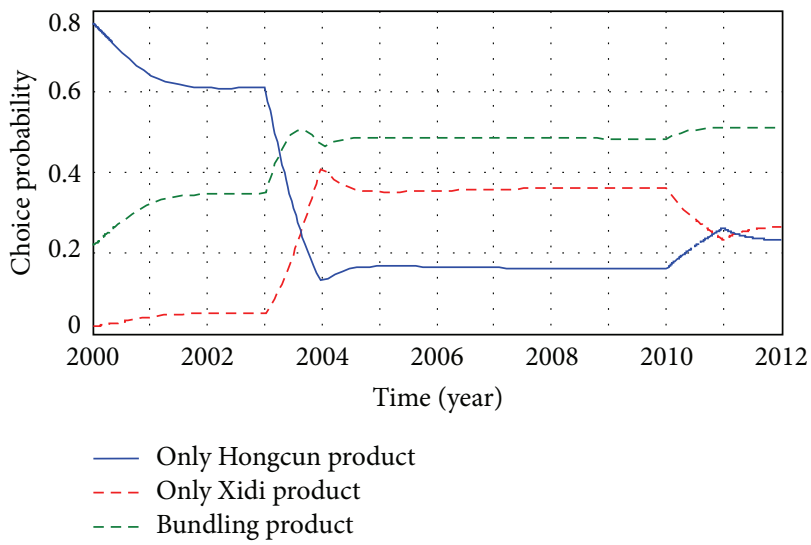

Figure 7: Simulated tourist choice ratios of different products (2000-2012).

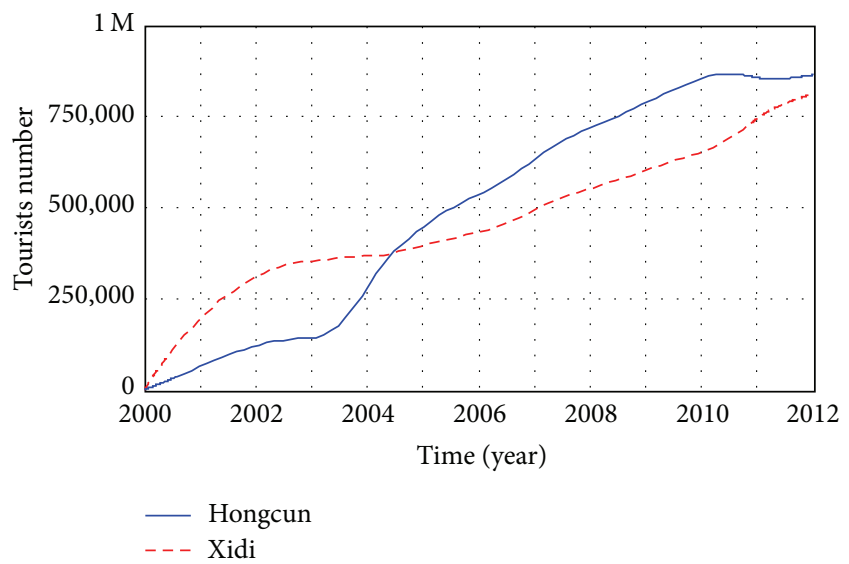

FIGURE 8: Simulated tourist numbers for Xidi and Hongcun (20002012).

4.2. Cooperation on Road Infrastructure Investment. This scenario demonstrates the competition and the cooperation on road infrastructure investment between Xidi and Hongcun with the simulation time from 2000 to 2018, especially the cooperation process which starts with the opening of the $\mathrm{Xi}$ Hong Road in 2013. All other variables are set as in Scenario 1, except the adding of touring time data after 2013 to the model (as shown in Table 2).

As shown in Figure 9, the ratios of both the Hongcun only and Xidi only products drop drastically with the opening of the Xi-Hong Road, but there is a significant increase in 


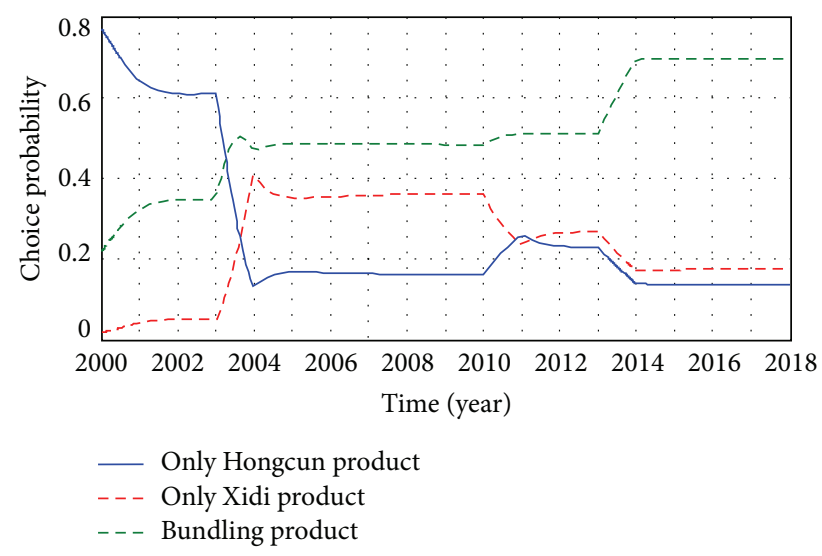

FIGURE 9: Simulated market share of different products (2000-2018).

the ratio of the bundling product, which rises to almost $70 \%$ of total tourism after 2013 . The cooperation on the road infrastructure investment is much better than that of competition, although the competition in the end also benefits the two through positive externality. Moreover, as a majority of tourists (almost 70\%) choose the bundling product, two villages are binding tightly through the improvement on the regional road network. Xidi and Hongcun can then be viewed as one destination with more and more road investment which can effectively improve the regional accessibility. Figure 10 shows that the proportion of visitors to both Xidi and Hongcun rises with the opening of the Xi-Hong Road, and the tourist revenue will also increase with the opening of the Xi-Hong Road for both villages, although the total tourist numbers to this region do not increase. It should be noted that the increased revenues can only be obtained by cooperation, since the increased visitors result from the increased share of the bundling product caused by the new Xi-Hong Road.

4.3. Discussion. The opening of the new transport infrastructure improves the accessibility of the whole region and thereby increases the market share of the region, which is proved by the fact that the growth of tourist numbers for both Xidi and Hongcun is higher than the growth of tourist numbers for Mt. Huang between 2000 and 2008. Although the opening of the Hong-Ru Road reduces the market share for Xidi, it does not reduce actual tourist arrivals. The positive externality of the Hong-Ru Road generally makes Xidi better off because the total number of tourists that visit the bundled products increases. The ratio for the bundling product increases from $22 \%$ to $70 \%$ with the opening of new and cooperated roads in the region of Xidi and Hongcun, demonstrating that the relationship between two destinations turns from the competition to the cooperation. In fact, the tendency of cooperation is independent of the construction order of the new roads. The relationship of cooperation is achieved when the road infrastructure is completed and finally the two destinations merge into one with the investments of road infrastructure in the whole region.

From simulation results, the local management can learn two development strategies of transport infrastructure

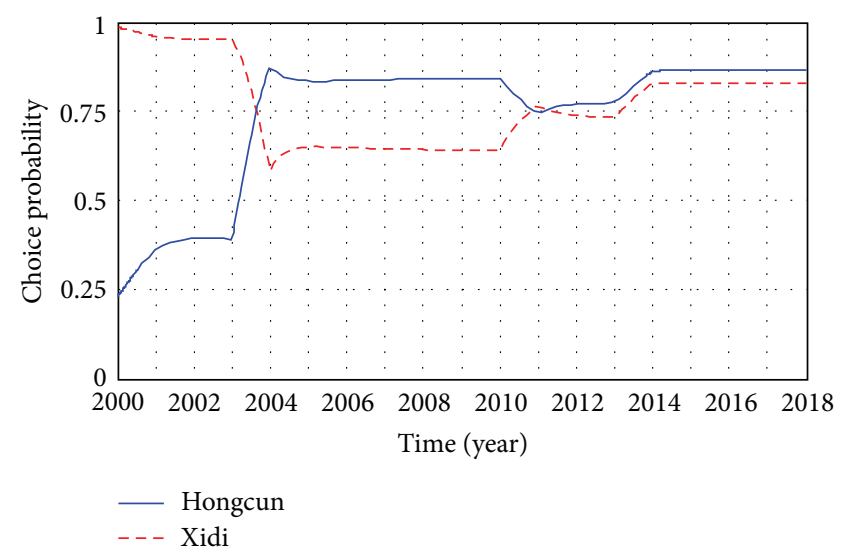

FIgURE 10: Simulated proportions of destination choices (20002018).

investment: one is to build a road to shorten the distance to the major tourist market and the other is building a road to connect with other local destinations. The former strategy aims to make the destination itself more accessible to tourists, while the latter attempts to make the bundling product more attractive. Each tourism destination management wants to achieve success by the improvement of its transport infrastructure. Actually the competition for road infrastructure investment can finally make two destinations better off even when all the decisions are totally based on the selfishness, but the investor in the road infrastructure gets more benefits than the free rider. The cooperation on road infrastructure investment can make both destinations better off by raising the ratio of the bundling product to a greater extent. Therefore both the competition and the cooperation on the transportation infrastructure investment can bring about a win-win situation for two destinations.

\section{Conclusions}

The influence of the road infrastructure on the tourism development of tourist destinations is a dynamic process in practice. In order to simulate the dynamic interaction of the road investment, tourist choice behavior, and destination land management, a quantitative method combining the system dynamics with a multinomial logit model is presented in this paper. The positive externality of road infrastructure on multiple tourism destinations is explicitly considered through feedback loops. Generally tourism destinations always compete for the transport infrastructure to improve their market share. The study shows an interesting phenomenon that both competition and cooperation on road infrastructure investment can attract more tourists for destinations. Moreover, the relationship between two destinations in the case study turns from the competition to the cooperation with the continuous growth of the choice ratio of the bundling product, which means the two destinations may merge into one with the improvement of the local road network. The case of Xidi and Hongcun provides a wonderful chance for observing and simulating the interaction 
between the tourism and the transport infrastructure and demonstrates that free competition for road infrastructure on multiple destinations can bring about a win-win situation for both villages. In view of results of the study, we suggest the management of tourism destinations builds road infrastructure to shorten the distance to the major market and to connect to adjacent destinations.

Future work will involve the application of the proposed method to cases of more than two destinations, and the proposed method is valuable in analyzing the investments of other kinds of transport infrastructure. A more complicated model with consideration of more factors such as investment cost will also be the subject of a future study.

\section{Conflict of Interests}

The authors declare that there is no conflict of interests regarding the publication of this paper.

\section{Acknowledgment}

This research was funded by the National Natural Science Foundation of China (no. 51178475).

\section{References}

[1] J. B. Odoki, H. R. Kerali, and F. Santorini, "An integrated model for quantifying accessibility-benefits in developing countries," Transportation Research Part A: Policy and Practice, vol. 35, no. 7, pp. 601-623, 2001.

[2] J. E. Dickinson, D. Robbins, and J. Fletcher, "Representation of transport. A rural destination analysis," Annals of Tourism Research, vol. 36, no. 1, pp. 103-123, 2009.

[3] J. Olsson, "Improved road accessibility and indirect development effects: evidence from rural Philippines," Journal of Transport Geography, vol. 17, no. 6, pp. 476-483, 2009.

[4] M. Kozak and M. Rimmington, "Tourist satisfaction with Mallorca, Spain, as an off-season holiday destination," Journal of Travel Research, vol. 38, no. 3, pp. 260-269, 2000.

[5] J. L. McElroy, "Small is land tourist economies across the life cycle," Asia Pacific Viewpoint, vol. 47, no. 1, pp. 61-77, 2006.

[6] P. Murphy, M. P. Pritchard, and B. Smith, "The destination product and its impact on traveller perceptions," Tourism Management, vol. 21, no. 1, pp. 43-52, 2000.

[7] J. L. Crompton and P. K. Ankomah, "Choice set propositions in destination decisions," Annals of Tourism Research, vol. 20, no. 3, pp. 461-476, 1993.

[8] C. A. Martin and S. F. Witt, "Substitute prices in models of tourism demand," Annals of Tourism Research, vol. 15, no. 2, pp. 255-268, 1988.

[9] G. I. Crouch, "Demand elasticities for short-haul versus longhaul tourism," Journal of Travel Research, vol. 33, no. 2, pp. 2-7, 1994.

[10] H.-Y. Shih, "Network characteristics of drive tourism destinations: an application of network analysis in tourism," Tourism Management, vol. 27, no. 5, pp. 1029-1039, 2006.

[11] B. Prideaux, "The role of the transport system in destination development," Tourism Management, vol. 21, no. 1, pp. 53-63, 2000 .
[12] J. D. Neal, M. J. Sirgy, and M. Uysal, "The role of satisfaction with leisure travel/tourism services and experience in satisfaction with leisure life and overall life," Journal of Business Research, vol. 44, no. 3, pp. 153-161, 1999.

[13] Y. Reisinger, B. Dimitrios, and C. Carlos, "Travel/tourism: spiritual experiences," in Tourism Business Frontiers: Consumers, Products and Industry, Butterworth-Heinemann, Oxford, UK, 2006.

[14] M. Schiefelbusch, A. Jain, T. Schäfer, and D. Müller, “Transport and tourism: roadmap to integrated planning developing and assessing integrated travel chains," Journal of Transport Geography, vol. 15, no. 2, pp. 94-103, 2007.

[15] W. Gronau and A. Kagermeier, "Key factors for successful leisure and tourism public transport provision," Journal of Transport Geography, vol. 15, no. 2, pp. 127-135, 2007.

[16] J. Khadaroo and B. Seetanah, "The role of transport infrastructure in international tourism development: a gravity model approach," Tourism Management, vol. 29, no. 5, pp. 831-840, 2008.

[17] K. Thompson and P. Schofield, "An investigation of the relationship between public transport performance and destination satisfaction," Journal of Transport Geography, vol. 15, no. 2, pp. 136-144, 2007.

[18] T. Takase and T. Morikawa, "Airport choice analysis of international passengers using time-series disaggregate data," Research in Transportation Economics, vol. 13, pp. 197-210, 2005.

[19] R. Zandvliet, M. Dijst, and L. Bertolini, "Destination choice and the identity of places: a disaggregated analysis for different types of visitor population environment in the Netherlands," Journal of Transport Geography, vol. 14, no. 6, pp. 451-462, 2006.

[20] J. W. Forrester, N. J. Mass, and C. J. Ryan, "The system dynamics national model: understanding socio-economic behavior and policy alternatives," Technological Forecasting and Social Change, vol. 9, no. 1-2, pp. 51-68, 1976.

[21] E. Frejinger, M. Bierlaire, and M. Ben-Akiva, "Sampling of alternatives for route choice modeling," Transportation Research Part B: Methodological, vol. 43, no. 10, pp. 984-994, 2009.

[22] F. Southworth, "Calibration of multinomial logit models of mode and destination choice," Transportation Research Part A: General, vol. 15, no. 4, pp. 315-325, 1981.

[23] S. Lu, L. Lu, L. Wang, Y. Wang, D. Liang, and Z. Yang, “Temporal characteristics of tourist flows to ancient villages: a case study of two cultural heritages, Xidi village and Hongcun village," Scientia Geographica Sinica, vol. 24, no. 2, pp. 250-256, 2004 (Chinese).

[24] Y. Zhang, J. Zhang, and H. Wang, "Analysis on the preference scale and competition state of in bound foreign tourist market of Huang Shan City," Human Geography, vol. 22, no. 2, pp. 4347, 2007 (Chinese).

[25] H. Xu and S. Dai, "A system dynamics approach to explore sustainable policies for Xidi, the world heritage village," Current Issues in Tourism, vol. 15, no. 5, pp. 441-459, 2012.

[26] S. Zhang and Y. Dong, "Viewing tourism development of world heritage of Xidi-Hongcun from tourist experience," East China Economic Management, vol. 2, pp. 43-46, 2006.

[27] Y. Wang, L. Lu, D. Zhang, P. Tao, and L. Wang, "Study on management system in ancient village resorts-case studies of Xidi and Hongcun, Yixian County," Journal of Anhui Normal University (Natural Science), vol. 29, no. 3, pp. 294-297, 2006. 
[28] S. Lu, L. Lu, M. Xu et al., "A research on tourism environmental carrying capacity of ancient villages: a case study of world cultural heritage Xidi village," Geographical Research, vol. 24, no. 4, pp. 581-590, 2005 (Chinese). 


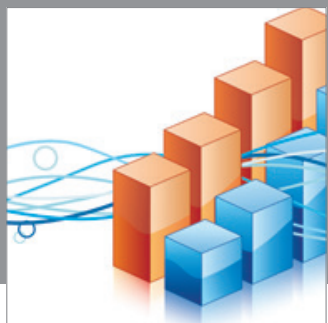

Advances in

Operations Research

mansans

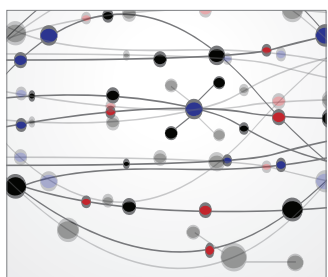

The Scientific World Journal
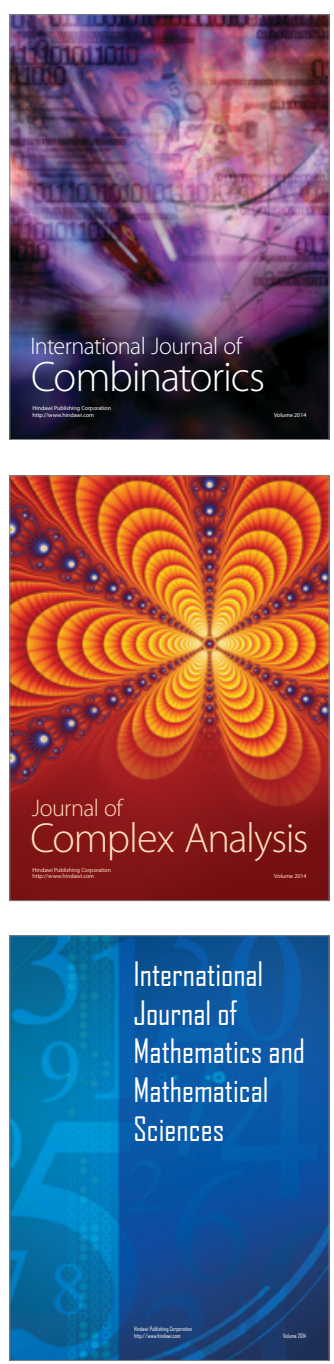
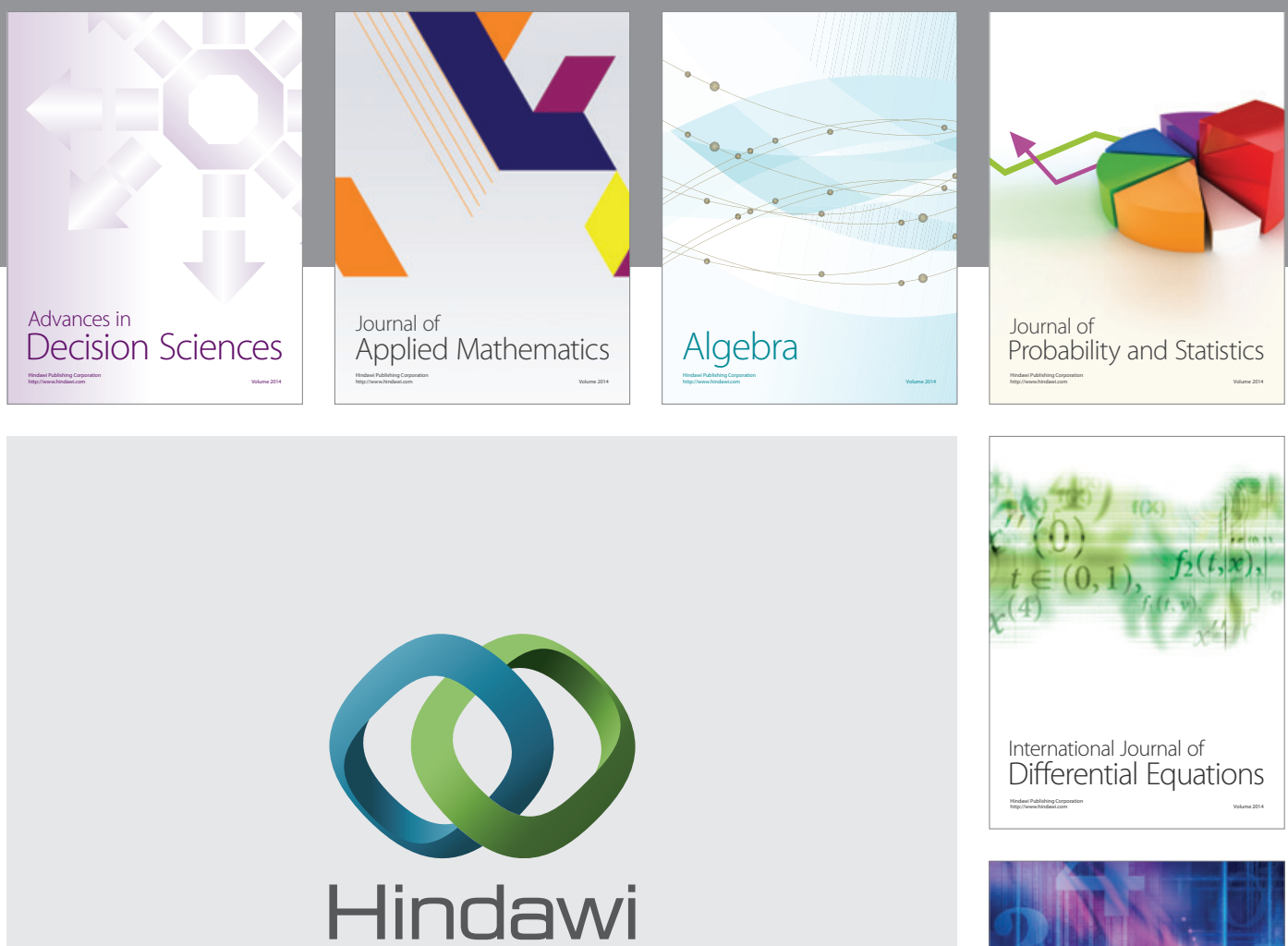

Submit your manuscripts at http://www.hindawi.com
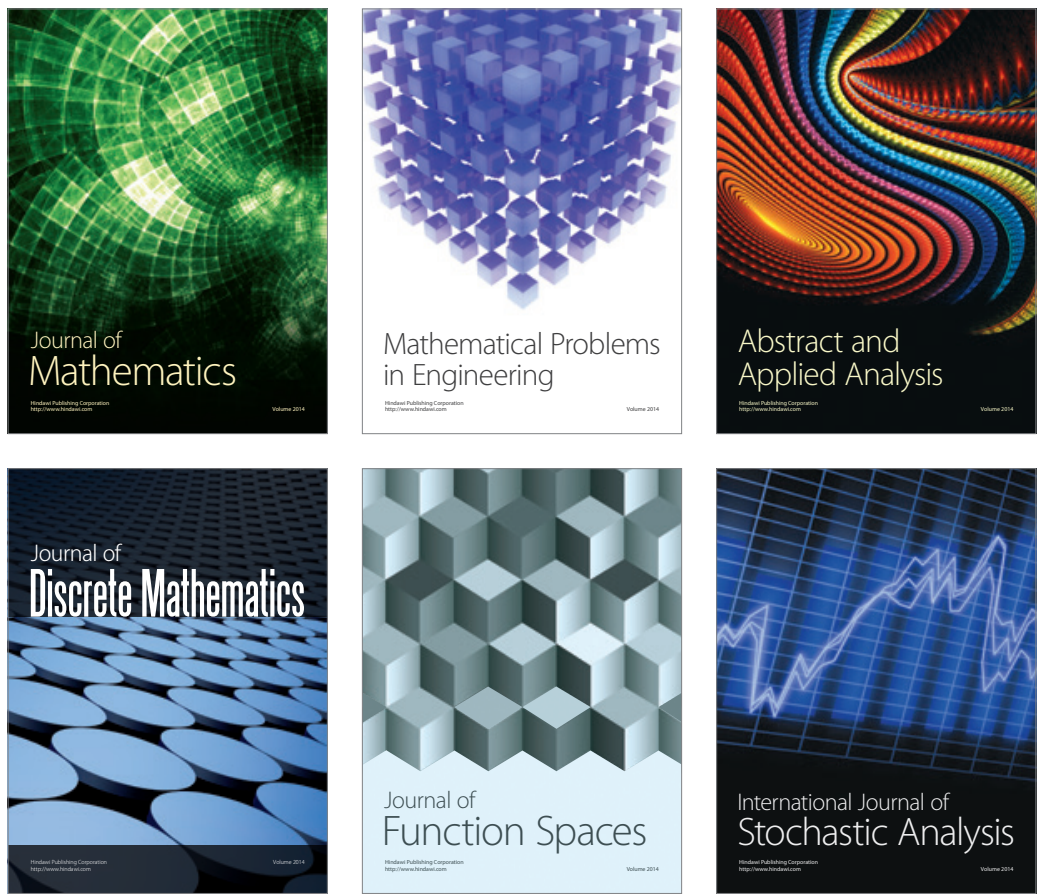

Journal of

Function Spaces

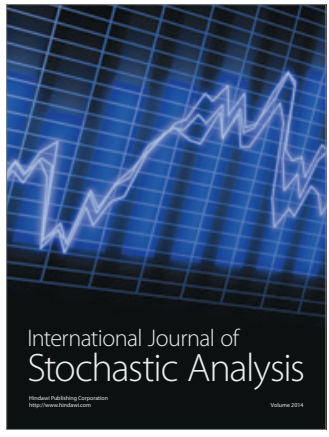

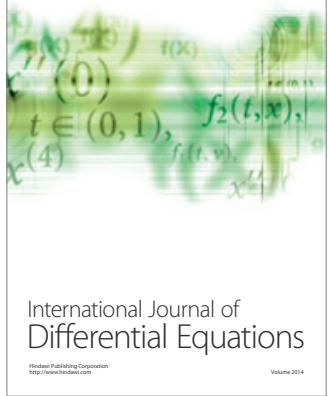
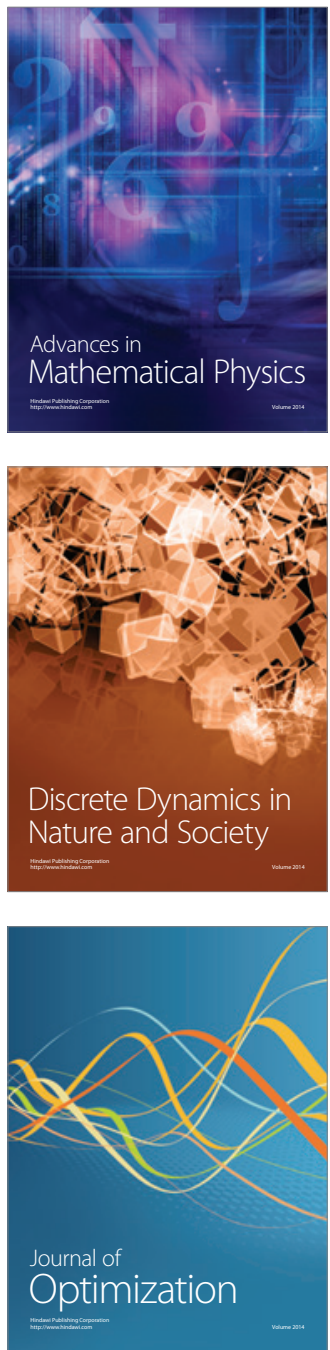